\title{
Optimized Dickey-Fuller Test Refines Sign and Boundary Problems Compare to Traditional Dickey-Fuller Test
}

\author{
Masudul Islam ${ }^{1,4}$, Afroza Akhtar ${ }^{2}$, Sirajum Munira ${ }^{3}$, Md. Salauddin Khan ${ }^{4} \&$ Md Monzur Murshed $^{5}$ \\ ${ }^{1}$ Department of Mathematical Science, Ball State University, USA. \\ ${ }^{2}$ Beximco Pharmaceuticals Limited, Bangladesh. \\ ${ }^{3}$ Department of Statistics, Jahangirnagar University, Savar, Dhaka. \\ ${ }^{4}$ Statistics Discipline, Khulna University, Khulna, Bangladesh. \\ ${ }^{5}$ Department of Mathematical Science, Ball State University, USA. \\ Correspondence: Masudul Islam, Department of Mathematical Science, Ball State University, USA. \\ Tel: 1-765-400-9873. E-mail: mislam4@bsu.edu
}

Received: May 21, 2018 Accepted: June 8, 2018 Online Published: August 3, 2018

doi:10.5539/ijsp.v7n5p19 URL: https://doi.org/10.5539/ijsp.v7n5p19

\begin{abstract}
Impede nonstationarity is vigorous to study performance of time series data and removes long-term components to expose any regular short-term regularity. So, we find miscellaneous unit root tests for instance Dickey-Fuller test, Augmented Dickey-Fuller plus DF-GLS Tests and identify that almost all unit root tests with the estimated model suffer from sign and boundary problems of the parameters to smooth the progress of the non-stationarity problem. In this paper, we usage Dickey-Fuller test and impose some limits on the parameter. Our proposed optimized DF test based on error sum of square (ESS). Monto Carlo simulation method is used to generate simulated critical values for different sample size. Our proposed optimized DF test gives better result than the ordinary DF test with effectiveness, uniformity and power properties. Also, optimized DF improves the sign and boundary problems through imposing some limit on error sum of squares and capture more nonstationarity of time related data.
\end{abstract}

Keywords: Optimized Dickey-Fuller test, Non-stationarity, ESS, Sign and boundary problems

\section{Introduction}

Socio-economic, statistical, time series, econometrics or econometric era are pedestal on a few exact postulations. Infringement of theories greatly influences the guess of the parameter over and above test of hypothesis (Akter, 2014). Nonstationary test is necessary for analyzing the activities of advance time series research. Usually non-stationarity can be tested by different unit root tests for example Dickey-Fuller (DF) test, Augmented Dickey-Fuller (ADF) test, DF-GLS Tests, Phillips-Perron (PP) test and Kwiatkowski-Phillips-Schmidt-Shin (KPSS) test discussed by Dickey and Fuller,1979; Kwiatkowski et al.,1992; Kodde and Palm, 1986). But all the unit root tests as well as the estimated model suffer from sign and boundary tribulations of the parameters (Akter and Majumder, 2013). So, appropriate testing procedure plays key role at the preliminary arena of any inquiries. In keeping with the assumption of the Dickey-Fuller test, $|\rho|<1$ or $-2<\delta<0$ of the time series models, such as $w_{i}=\rho w_{i-1}+u_{i}$. Any estimated value of $\delta<-2$ or $\delta>0$ may fallout in invalid model for making decision regarding nonstationarity (Naznin et al., 2014). To triumph over this condition, it is required to impose appropriate limits on the parameters, which is larger than zero. Very diminutive quantity of literatures is on this concern such as Majumder and King (1999) proposed one sided tests. Basak et al. (2005) and Rois et al. (2008) worked on distance based approach. Aktar and Majumder (2013) developed one sided DF testing procedure. Naznin et al (2014) showed the sign and boundary problems and solution by Augmented Dickey-Fuller (ADF) test. Hence the usual DF test for testing unit root is not always fit and we need to enlarge constrained parameter estimation on restricted DF test. So, we are provoked to expand a suitable testing technique. The principle of this paper is, firstly test the stationarity of some observed time series. Secondly, propose the testing approach due to arising some unit root problems. Finally, compare the proposed test with the usual test. 


\section{Method}

\subsection{Unit Root Tests}

\subsubsection{Dickey Fuller Test}

Dickey and Fuller suggested that under the null hypothesis the estimated coefficient of $w_{t-1}$ in the model (1) follows the $\tau$ statistic is known as Dickey-Fuller test. Here, errors are serially uncorrelated. In principle, three specifications can be tried, depending on whether the series show a trend or not. Allowing the various possibilities, DF test is estimated in three different forms under different null hypothesis for the following models,

$$
\Delta w_{t}=\delta w_{t-1}+\varepsilon_{t}, \Delta w_{t}=\beta_{1}+\delta w_{t-1}+\varepsilon_{t}, \Delta w_{t}=\beta_{1}+\beta_{2} t+\delta w_{t-1}+\varepsilon_{t}
$$

where $t$ is the time or trend variable. In each case, $H_{0}: \delta=0$ means the time series is non-stationary and $H_{1}: \delta<0$ means the time series is stationary. If $H_{0}$ is rejected, is $w_{t}$ stationary with nonzero mean $\left[\frac{\beta_{1}}{(1-\rho)}\right]$ for the second model and $w_{t}$ is stationary around a deterministic trend for third model. If the critical absolute value of the $\tau$ statistic exceeds the DF or Mackinnon DF absolute critical $\tau$ values, then we don't reject the hypothesis that the given time series is stationary. If it is less than the critical value, the time series is non-stationary (Gujarati, 2003).

\subsubsection{Augmented Dickey-Fuller Test}

Said and Dickey (1984) advised the autoregressive unit root test to accommodate general ARMA $(p, q)$ models with unknown orders and their test is referred to as the Augmented Dickey-Fuller (ADF) test (Said and Dickey, 1984). For $\mathrm{ADF}$, tests the null hypothesis, a time series $\Delta w_{t}$ is $I(1)$ against the alternative is $I(1)$, assume the dynamics in the data have an ARMA structure. The ADF is based on estimating the test regression

$$
\Delta w_{t}=\alpha_{0}+\alpha_{1}+\delta w_{t-1}+\sum_{i=1}^{m} \beta_{i} \Delta w_{t-i}+\varepsilon_{t}
$$

where, $t$ is the time or trend and $\rho-1=\delta, \varepsilon_{t}$ is a white noise, $\alpha_{0}$ is an intercept and $\alpha_{1}, \delta, \beta_{i}$ are coefficients(Gujarati, 2003).

\subsubsection{DF-GLS Tests}

DF-GLS tests perform the customized Dickey-Fuller $t$ test proposed by Elliott et al. (1996). Basically, the assessment is similar to augmented Dickey-Fuller test and performed by Stata's dfuller command, except that the time series is transformed via GLS regression before carrying out the analysis. Elliott et al. later studies have revealed the unknown parameters $\beta$ of the trend function are efficiently estimated under the alternative model with $\bar{\phi}=1+\bar{c} / T$ i.e., $\hat{\beta}_{\bar{\phi}}=\left(D_{\phi}^{\prime} D_{\bar{\phi}}\right)^{-1} D_{\phi}^{\prime} y_{\bar{\phi}} \quad$ (Dickey and Fuller, 1979). ERS use this insight to derive ADF t-statistic, which they call the DF-GLS test. They construct this $t$-statistic as follows. Firstly, using the trend parameters $\hat{\beta}_{\bar{\phi}}$ estimated under the alternative, define the detruded data $w_{t}^{d}=w_{t}-\hat{\beta}_{\bar{\phi}}^{\prime} D_{t}$. Next, using GLS, estimate ADF test regression which omits the deterministic terms $\Delta w_{t}^{d}=\pi w_{t-1}^{d}+\sum_{j=1}^{p} \psi_{j} \Delta w_{t-j}^{d}+\varepsilon_{t}$ and compute the $t$-statistic for testing $\pi=0$ (Chatfield, 2003).

\subsection{Modified Dickey-Fuller Test}

Dickey-Fuller test is the most commonly used unit root test for testing stationarity. The Dickey-Fuller test can be related to the three models as follows:

$$
\begin{gathered}
w_{t}=\rho w_{t-1}+\varepsilon_{t} \text { or } \Delta w_{t}=\delta w_{t-1}+\varepsilon_{t} \\
w_{t}=\alpha+\rho w_{t-1}+\varepsilon_{t} \text { or } \Delta w_{t}=\alpha+\delta w_{t-1}+\varepsilon_{t} \\
w_{t}=\alpha+\beta t+\rho w_{t-1}+\varepsilon_{t} \text { or } \Delta w_{t}=\alpha+\beta t+\delta w_{t-1}+\varepsilon_{t}
\end{gathered}
$$

where, $t$ is the time or trend variable. For (4), when a time series is trend stationary, then the coefficient of time $\beta$ may be either positive $(\beta>0$ for upward trend) or negative $(\beta<0$ for downward trend). Hence, the parameter $\beta$ is also restricted. We observed that the ignoring of the two restrictions may result in three different problems, (i) estimated parameters values will be overestimated, (ii) test statistic based on this estimate may produce loss in power, (iii) estimated models may be invalid. So, if $\beta$ is strictly affirmative or pessimistic the subsequent model will be more appropriate. In 
matrix notation (4) may written as,

$$
W=X \beta+\varepsilon,
$$

$$
\left[\begin{array}{c}
w_{1} \\
w_{2} \\
\vdots \\
w_{T}
\end{array}\right]=\left[\begin{array}{ccc}
1 & 1 & w_{0} \\
1 & 2 & w_{1} \\
\vdots & \vdots & \vdots \\
1 & T & w_{T-1}
\end{array}\right]\left[\begin{array}{c}
\alpha \\
\beta \\
\rho
\end{array}\right]+\left[\begin{array}{c}
\varepsilon_{1} \\
\varepsilon_{2} \\
\vdots \\
\varepsilon_{T}
\end{array}\right] \text {, where } W=\left[\begin{array}{c}
w_{1} \\
w_{2} \\
\vdots \\
w_{T}
\end{array}\right], \quad X=\left[\begin{array}{ccc}
1 & 1 & w_{0} \\
1 & 2 & w_{1} \\
\vdots & \vdots & \vdots \\
1 & T & w_{T-1}
\end{array}\right], \varepsilon=\left[\begin{array}{c}
\varepsilon_{1} \\
\varepsilon_{2} \\
\vdots \\
\varepsilon_{T}
\end{array}\right], \beta=\left[\begin{array}{c}
\alpha \\
\beta \\
\rho
\end{array}\right]^{\prime}
$$

Or,

$$
\Delta W=X \Gamma+\varepsilon
$$

$$
\left[\begin{array}{c}
\Delta w_{1} \\
\Delta w_{2} \\
\vdots \\
\Delta w_{T}
\end{array}\right]=\left[\begin{array}{ccc}
1 & 1 & w_{0} \\
1 & 2 & w_{1} \\
\vdots & \vdots & \vdots \\
1 & T & w_{T-1}
\end{array}\right]\left[\begin{array}{c}
\alpha \\
\beta \\
\rho
\end{array}\right]+\left[\begin{array}{c}
\varepsilon_{1} \\
\varepsilon_{2} \\
\vdots \\
\varepsilon_{T}
\end{array}\right] \text {, where } \Delta W=\left[\begin{array}{c}
\Delta w_{1} \\
\Delta w_{2} \\
\vdots \\
\Delta w_{T}
\end{array}\right], X=\left[\begin{array}{ccc}
1 & 1 & w_{0} \\
1 & 2 & w_{1} \\
\vdots & \vdots & \vdots \\
1 & T & w_{T-1}
\end{array}\right], \varepsilon=\left[\begin{array}{c}
\varepsilon_{1} \\
\varepsilon_{2} \\
\vdots \\
\varepsilon_{T}
\end{array}\right], \Gamma=\left[\begin{array}{l}
\alpha \\
\beta \\
\rho
\end{array}\right]
$$

where, we impose some limits on parameters and guess the model using constraint optimization subroutine and appropriate modification. Thus, we minimize the ESS by subsequent approach to estimate the model appropriately. Minimizing, $E S S=(W-X \beta)^{\prime} \Sigma^{-1}(W-X \beta),|\rho|<1, \beta>0$ or $\beta<0$, or

Minimizing, $E S S=(W-X \Gamma)^{\prime} \Sigma^{-1}(W-X \Gamma),-2<\tilde{\delta}<0, \beta>0$ or $\beta<0$

where, $\beta>0$ for upward trend or $\beta<0$ for downward trend. If we can provide the Hessian or Jacobian, the optimization process will be quicker. The Hessian matrix can be gained by differencing ESS successively two times relating to the parameters,

$$
\theta=\left(\begin{array}{lll}
\alpha & \beta & \rho
\end{array}\right), H(\theta)=\frac{\partial^{2} E S S}{\partial \theta^{2}}=\left[\begin{array}{lll}
\frac{\partial^{2} E S S}{\partial \alpha^{2}} & \frac{\partial^{2} E S S}{\partial \alpha \partial \beta} & \frac{\partial^{2} E S S}{\partial \alpha \partial \rho} \\
\frac{\partial^{2} E S S}{\partial \alpha \partial \beta} & \frac{\partial^{2} E S S}{\partial \beta^{2}} & \frac{\partial^{2} E S S}{\partial \beta \partial \rho} \\
\frac{\partial^{2} E S S}{\partial \alpha \partial \rho} & \frac{\partial^{2} E S S}{\partial \beta \partial \rho} & \frac{\partial^{2} E S S}{\partial \rho^{2}}
\end{array}\right], \quad J(\theta)=\frac{\partial E S S}{\partial \theta}=\left[\begin{array}{l}
\frac{\partial E S S}{\partial \alpha} \\
\frac{\partial E S S}{\partial \beta} \\
\frac{\partial E S S}{\partial \rho}
\end{array}\right]
$$

and the information matrix,

$$
I(\theta)=-E[H(\theta)]=-E\left[\begin{array}{lll}
\frac{\partial^{2} E S S}{\partial \alpha^{2}} & \frac{\partial^{2} E S S}{\partial \alpha \partial \beta} & \frac{\partial^{2} E S S}{\partial \alpha \partial \rho} \\
\frac{\partial^{2} E S S}{\partial \alpha \partial \beta} & \frac{\partial^{2} E S S}{\partial \beta^{2}} & \frac{\partial^{2} E S S}{\partial \beta \partial \rho} \\
\frac{\partial^{2} E S S}{\partial \alpha \partial \rho} & \frac{\partial^{2} E S S}{\partial \beta \partial \rho} & \frac{\partial^{2} E S S}{\partial \rho^{2}}
\end{array}\right] \text { where, where, } \theta=\left(\begin{array}{lll}
\alpha \beta & \rho
\end{array}\right),
$$

Here, we relate the constraint distance-based approach using information matrix. Shiparo (1988), Kodde and Palm's (1986), Majumder and King (1999) suggests that we should determine the closest point in the maintained hypothesis from the unconstrained point. The closest point is the solution of the following distance or optimal function of the parameter vector $\hat{\theta}$. $\|\tilde{\theta}-\hat{\theta}\|_{\delta}=(\tilde{\theta}-\hat{\theta})^{\prime} I(\theta)(\tilde{\theta}-\hat{\theta}), \tilde{\theta} \varepsilon \beta$. Our proposed $\tau$ - statistic is based on the optimized estimates as follows, $\tilde{\tau}=\frac{\delta}{S E(\tilde{\delta})}$ where, $\tilde{\tau}$ is the optimized $\tau$ statistic and $\tilde{\delta}, \tilde{\beta}$ are the optimized estimate of the parameters. The $\tau$ - statistic follow the weighted mixture $\tau$ - distribution (Majumder, and King, 1999).

\section{Results}

To assess non-stationary, we used (1) diverse unit root tests, generating artificial data by Monto-Carlo simulation for early investigation, (Gujarati, 2003) 

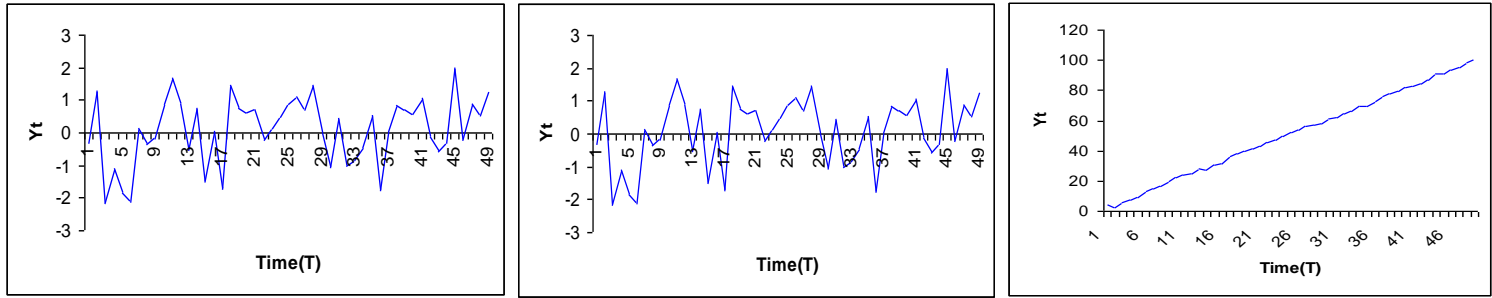

Fig 1.Time series plot for random walk model without drift, with drift and with drift and trend (Gujarati, 2003)

The above two figures facilitate there is no trend and more random movement in series $w_{t}$. Also, the series depends on time, so $w_{t}$ is non-stationary. The last one shows a well-built upward trend component which is important for initial analysis. While the series is non-stationary because it enlarges with time. Now we consider unit root test of pretend series $w_{t}$ and found that virtual random walk model with drift, without drift and with drift and trend shows nonstationary (Table-1). Since the complete assessment of the calculated $\tau$ is smaller than absolute DF critical values $(\alpha=5 \%)$. Once more, we take some time series of sell overseas of Bangladesh such as pelt, clothing, Jute etc. and graphically observe the time series data and unit root test.
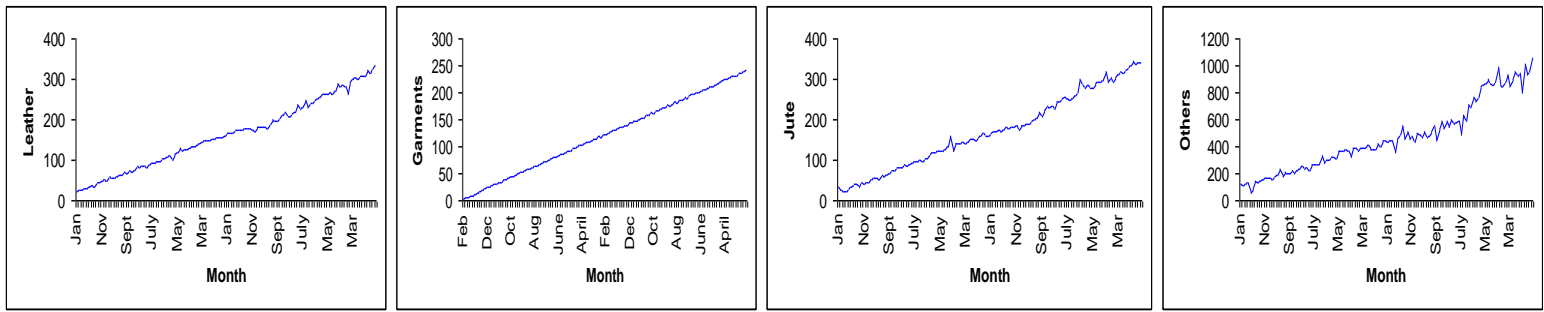

Fig 2. Plot for pelt, clothing, jute and additional rudiments from 2002 to 2015

Table 1. Unit root test of pelt, clothing, jute and additional rudiments

\begin{tabular}{|c|c|c|c|c|}
\hline & Model & $\tau$ values & $\begin{array}{c}(5 \%) \mathrm{DF} \\
\text { critical values }\end{array}$ & Decision \\
\hline \multirow[t]{3}{*}{ Pelt } & $\Delta p l_{i}=\delta p l_{i-1}+u_{i}$ & $11.67^{*}$ & -1.59 & Stationary $^{*}$ \\
\hline & $\Delta p l_{i}=\beta_{1}+\delta p l_{i-1}+u_{i}$ & $-7.03^{*}$ & -2.90 & Stationary $^{*}$ \\
\hline & $\Delta p l_{i}=\beta_{1}+\beta_{2} t+\delta p l_{i-1}+u_{i}$ & $-4.23^{*}$ & -3.55 & Stationary ${ }^{*}$ \\
\hline \multirow[t]{3}{*}{ Clothing } & $\Delta c l_{i}=\delta c l_{i-1}+u_{i}$ & $-8.65^{*}$ & -1.97 & Stationary ${ }^{*}$ \\
\hline & $\Delta c l_{i}=\beta_{1}+\delta c l_{i-1}+u_{i}$ & $11.68^{*}$ & -2.84 & Stationary $^{*}$ \\
\hline & $\Delta c l_{t}=\beta_{1}+\beta_{2} t+\delta c l_{t-1}+u_{t}$ & $-21.67^{*}$ & -3.55 & Stationary $^{*}$ \\
\hline \multirow[t]{3}{*}{ Jute } & $\Delta J l_{i}=\delta J l_{i-1}+u_{i}$ & $-1.77^{*}$ & -1.95 & Nonstationary $^{*}$ \\
\hline & $\Delta J l_{i}=\beta_{1}+\delta J l_{i-1}+u_{i}$ & $-10.66^{*}$ & -2.90 & Stationary ${ }^{*}$ \\
\hline & $\Delta J l_{i}=\beta_{1}+\beta_{2} t+\delta J l_{i-1}+u_{i}$ & $-8.45^{*}$ & -3.44 & Stationary ${ }^{*}$ \\
\hline \multirow{3}{*}{$\begin{array}{l}\text { Additional } \\
\text { rudiments }\end{array}$} & $\Delta a r_{i}=\delta a r_{i-1}+u_{i}$ & $19.32^{*}$ & -1.95 & Stationary ${ }^{*}$ \\
\hline & $\Delta a r_{i}=\beta_{1}+\delta a r_{i-1}+u_{i}$ & $-1.26^{*}$ & -2.90 & Nonstationary $^{*}$ \\
\hline & $\Delta a r_{i}=\beta_{1}+\beta_{2} t+\delta a r_{i-1}+u_{i}$ & $-9.20^{*}$ & -3.23 & Stationary $^{*}$ \\
\hline
\end{tabular}

Analyzing the above graphs and tables we perceive that standard testing approach is not suitable for all cases. In several cases, calculated $\tau$ is positive which describes the invalidity of the respective model. We also consider co-integration test between pelt and clothing as well as jute and additional rudiments. Surprising found that pelt and clothing are not co-integrated whereas jute and additional rudiments are co-integrated but some cases the $\tau$ statistic confirm positive 
value that mislead the model (Table-2). In these models, we then test the hypothesis $H_{0}: \beta=0$, against $H_{a}: \beta>0, \beta<$ 0 , and set $\alpha=0.02$ and $\beta=0.01$. We find that, as sample sizes increases, the generated critical values for any sample size, which are approximately same as the critical values in the Dickey-Fuller table (Table-3). Thus, standard unit root test shows some of the series stationary and cannot capture the non-stationary problem in the approved manner. The incorrect identification may occur due to ignoring the restrictions on the parameters of models. So, estimation procedure need restricted estimation taking error term of two non-stationary series based on minimizing the ESS. For restricted parameter under alternative, the constraint optimization requires sophisticated optimization subroutine. Hence, we introduce Modified Dickey-Fuller Test and estimate the parameters by using newly proposed restricted test based on ESS and compares power of the existing Dickey-Fuller tests and the newly proposed restricted test.

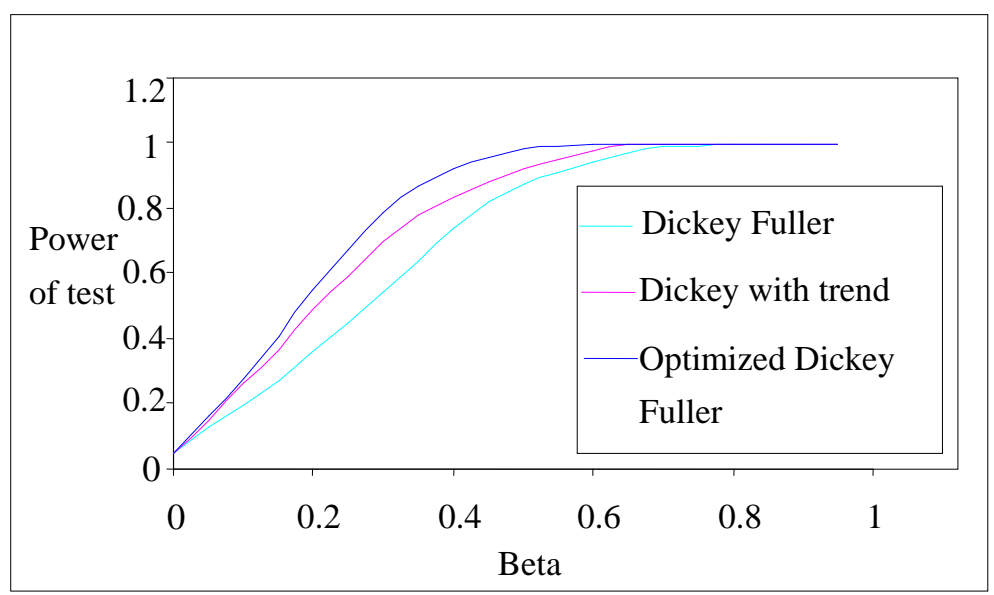

Fig 3. Power curve of standard Dickey-Fuller test and Optimized test

We observed from table-5 and figure- 3 that the simulated power of the newly proposed test is always higher than the usual Dickey-Fuller test and the power of proposed optimized test converges to 1 more rapidly in compare with the usual test.

\section{Conclusion}

Usual Dickey-Fuller test suffer from sign and boundary problems of the parameters. This paper deals with optimized Dickey-Fuller test. So, we are wrapping up optimized method based on $\tilde{\tau}=(\tilde{\delta} / S E(\tilde{\delta}))$ restricted ESS of Dickey-Fuller test and observe that optimized Dickey-Fuller test gives better result than traditional Dickey-Fuller test with effectiveness, uniformity and power properties.

\section{References}

Akter, A. (2014). On some aspects of time series analysis. An unpublished thesis, Jahangirnagar University, Bangladesh.

Akter, R., \& Majumder, A.K. (2013). Restricted Testing Procedure and Modified Dickey-Fuller Test, Research Journal of Mathematical and Statistical Sciences, 1(5), 17-20.

Ara, I., \& King, M. L. (1993). Marginal likelihood-based tests of a subvector of the parameter vector of linear regression disturbances. In C.S. Forbes, P. Kofman and T.R.L. Fry (eds.), Proceeding of the Econometrics Conference at Monash University, Monash University, 69-106.

Basak, T., Rois, R., \& Majumder, A. K. (2005). One Sided Version of the Breusch-Godfrey test for Testing Higher-Order Autocorrelation-A Distance-Based Approach. Proceeding of the Two One-Day Seminars, Bangladesh Statistical Association, Dhaka.

Brockwell, P. J., \& Davis, R. A. (1996). Introduction to Time series and Forecasting, Springer, New York.

Chatfield, C. (2003). The Analysis of Time Series: An Introduction, $6^{\text {th }}$ ed., London: Chapman and Hall.

Dickey, D. A., \& Fuller, W. A. (1979). Distribution of the Estimators for Autoregressive Time series with A Unit Root, Journal of the American Statistical Association,74, 427-431. https://doi.org/10.1080/01621459.1979.10482531.

Elliott, G., Rothenberg, T. J., \& Stock, J. H. (1996). Efficient tests for an Autoregressive Unit Root, Econometrica, 64, 813-836. https://doi.org/10.2307/2171846.

Greene, W. H. (2000). Econometric Analysis, $4^{\text {th }}$ ed., Prentice Hall, Upper Saddle River, New Jersey. 
Gujarati, D. N. (2003). Basic Econometrics, $4^{\text {th }}$ ed., McGraw-Hill; New York.

Hall, A. (1994). Testing for a Unit Root in Time Series with Pretest Databased Model Selection, Journal of business and economic statistics. 12, 461-470.

Hamilton, J. D. (1994). Time Series Analysis, Princeton University press, New Jersey.

Johnston, J. (1997). Econometric Methods $4^{\text {th }}$ ed., McGraw-Hill; New York.

Kodde, D. A., \& Palm, F. C. (1986). LR criteria for jointly testing equality and inequality restrictions, Econometrica, 54, 1243-1248. https://doi.org/10.2307/1912331.

Kwiatkowski, D., Phillips, P. C. B., Schmidt, P., \& Shin Y. (1992). Testing the Null Hypothesis of Stationary against the Alternative of a Unit Root, Journal of Econometrics, 54, 159-178. https://doi.org/10.1016/0304-4076(92)90104-Y.

Maddala, G. S., \& Kim, I. (1998). Unit roots, Co-integration and Structural Change, Cambridge University press, UK.

Majumder, A. K., \& King, M. L. (1999). One sided test of multiple inequality constraints- a distance-based approach, Paper presented at the Econometric Society Australasian Meeting 7-10 July. Canberra.

Majumder, A. K. (1999). One-sided and partial one-sided hypothesis testing in econometrics. An unpublished thesis, Monash University, Australia.

Naznin, S., Poul, G. K., \& Majumder, A. K. (2014). Boundary and Sign Problems of Parameters along with its Solutions of the Augmented Dickey-Fuller Test, Global Journal of Science Frontier Research: F Mathematics and Decision Theory, 14, 55-60.

Park, J. Y. (1990). Testing for Unit Roots and Co-integration by Variable Addition, in T. Fom by and F. Rhodes (eds.) Advances in Econometrics: Co-integration, Spurious Regression and Unit Roots, Jai Press: Greenwich.

Park, J. Y., \& Choi, B. (1988). A new Approach to Testing for a Unit Root, CAE Working Paper 88-23, Cornell University.

Rois, R., Basak, T., \& Majumder, A. K. (2008). On the Test of Restricted Higher Order Autocorrelation: A Wald-Type Distance-Based Approach. Jahangirnagar University Journal of Science, 31(1), 127-142. Journal of Science Frontier Research: F Mathematics and Decision Theory, 14(5). 55-60.

Rois, R., Basak, T., \& Majumder, A. K. (2012). Marginal Likelihood-based One-sided LR Test for Testing Higher Order Autocorrelation in Presence of Nuisance Parameters: A Distance Based Approach, International Journal of Statistics and Probability, 1(2), 69-78. https://doi.org/10.5539/ijsp.v1n2p69.

Said, S. E., \& Dickey, D. (1984). Testing for Unit Roots in Autoregressive Moving-Average Models with Unknown Order, Handbook of Biometrika, and 71,599-607. https://doi.org/10.1093/biomet/71.3.599.

Schwert, G. W. (1989). Tests for unit roots: A Monte Carlo Investigation. Journal of Business and Economic Statistics, 2 , 147-159. https://doi.org/10.1198/073500102753410354.

Shapiro, A. (1988). Towards a unified theory of inequality constrained testing in multivariate analysis, International Statistical Review, 56, 49-62. https://doi.org/10.2307/1403361. 


\section{Appendix}

Table 2. Co-integration test of pelt, clothing, jute and additional rudiments

\begin{tabular}{llccl}
\hline Co-integration & Model & $\tau$ values & DFcritical values (5\%) & Decision \\
\hline Pelt and & $\Delta u_{t}=u_{t-1}+\varepsilon_{t}$ & 40.5482 & -1.948 & Not cointegrated \\
Clothing & $\Delta u_{t}=\alpha+u_{t-1}+\varepsilon_{t}$ & 1.578 & -2.891 & Not cointegrated \\
& $\Delta u_{t}=\alpha+\beta t+u_{t-1}+\varepsilon_{t}$ & 15.236 & -3.455 & Not cointegrated \\
\hline \multirow{2}{*}{ Jute and Others } & $\Delta u_{t}=u_{t-1}+\varepsilon_{t}$ & -1.284 & -1.948 & Cointegrated \\
& $\Delta u_{t}=\alpha+u_{t-1}+\varepsilon_{t}$ & 1.578 & -2.891 & Cointegrated \\
& $\Delta u_{t}=\alpha+\beta t+u_{t-1}+\varepsilon_{t}$ & -2.623 & -3.455 & Cointegrated
\end{tabular}

Table 3. Simulated $1 \%$ and 5\% critical Dickey-Fuller $\tau$ values for unit root tests

\begin{tabular}{ccccccc}
\hline \multirow{2}{*}{$\begin{array}{c}\text { Sample } \\
\text { Size }\end{array}$} & \multicolumn{7}{c}{$t_{n c}$} & \multicolumn{2}{c}{$t_{c}$} & $t_{c t}$ \\
\cline { 2 - 7 } & $1 \%$ & $5 \%$ & $1 \%$ & $5 \%$ & $1 \%$ & $5 \%$ \\
\hline & & & & & \\
\hline 25 & -2.63 & -1.95 & -3.86 & -3.09 & -4.55 & -3.79 \\
50 & -2.62 & -1.97 & -3.63 & -2.97 & -4.14 & -3.54 \\
100 & -2.60 & -1.97 & -3.55 & -2.92 & -3.59 & -2.91 \\
250 & -2.60 & -1.96 & -3.47 & -2.88 & -2.69 & -2.00 \\
500 & -2.57 & -1.94 & -3.44 & -2.86 & -2.48 & -1.79 \\
$\infty$ & -2.55 & -1.94 & -3.45 & -2.52 & -2.48 & -1.77 \\
\hline
\end{tabular}

Table 4. Generated critical value of Dickey-Fuller table for Sample size $n=20,21, \ldots, 1000$

\begin{tabular}{lcccccc}
\hline Sample size & \multicolumn{2}{c}{$t_{n c}$} & \multicolumn{2}{c}{$t_{c}$} & \multicolumn{2}{c}{$t_{c t}$} \\
\hline 20 & $1 \%$ & $5 \%$ & $1 \%$ & $5 \%$ & $1 \%$ & $5 \%$ \\
21 & -2.6955 & -1.9591 & -3.8084 & -3.0207 & -4.4991 & -3.6584 \\
22 & -2.6796 & -1.9581 & -3.7879 & -3.0123 & -4.4685 & -3.6449 \\
23 & -2.6742 & -1.9572 & -3.7695 & -3.0048 & -4.4407 & -3.6328 \\
24 & -2.6693 & -1.9564 & -3.7528 & -2.9981 & -4.4162 & -3.6219 \\
25 & -2.6648 & -1.9557 & -3.7381 & -2.9918 & -4.3942 & -3.6121 \\
26 & -2.6607 & -1.9550 & -3.7242 & -2.9862 & -4.3741 & -3.6032 \\
27 & -2.6569 & -1.9544 & -3.7116 & -2.9810 & -4.3559 & -3.5950 \\
28 & -2.6534 & -1.9538 & -3.7000 & -2.9762 & -4.3392 & -3.5875 \\
29 & -2.6501 & -1.9533 & -3.6893 & -2.9718 & -4.3238 & -3.5806 \\
30 & -2.6471 & -1.9528 & -3.6794 & -2.9677 & -4.3097 & -3.5742 \\
31 & -2.6443 & -1.9524 & -3.6702 & -2.9639 & -4.2966 & -3.5683 \\
32 & -2.6417 & -1.9520 & -3.6617 & -2.9604 & -4.2844 & -3.5628 \\
\hline
\end{tabular}




\begin{tabular}{|c|c|c|c|c|c|c|}
\hline 33 & -2.6369 & -1.9512 & -3.6463 & -2.9540 & -4.2626 & -3.5529 \\
\hline 34 & -2.6348 & -1.9509 & -3.6393 & -2.9511 & -4.2528 & -3.5484 \\
\hline 35 & -2.6327 & -1.9506 & -3.6328 & -2.9484 & -4.2435 & -3.5442 \\
\hline 36 & -2.6308 & -1.9503 & -3.6267 & -2.9458 & -4.2349 & -3.5402 \\
\hline 37 & -2.6292 & -1.9501 & -3.6209 & -2.943 & -4.2267 & -3.5365 \\
\hline 38 & -2.6275 & -1.9497 & -3.6155 & -2.9411 & -4.2190 & -3.5330 \\
\hline 39 & -2.6258 & -1.9495 & -3.6103 & -2.9389 & -4.2118 & -3.5297 \\
\hline 40 & -2.6243 & -1.9493 & -3.6055 & -2.9369 & -4.2049 & -3.5265 \\
\hline 41 & -2.6228 & -1.9490 & -3.6009 & -2.9350 & -4.1984 & -3.5236 \\
\hline 42 & -2.6214 & -1.9488 & -3.5965 & -2.9331 & -4.1923 & -3.5207 \\
\hline 43 & -2.6201 & -1.9486 & -3.5923 & -2.9314 & -4.1864 & -3.5180 \\
\hline 44 & -2.6188 & -1.9484 & -3.5884 & -2.9297 & -4.1808 & -3.5155 \\
\hline 45 & -2.6176 & -1.9483 & -3.5846 & -2.9281 & -4.1758 & -3.5130 \\
\hline 46 & -2.6164 & -1.9481 & -3.5810 & -2.9266 & -4.1707 & -3.5107 \\
\hline 47 & -2.6153 & -1.9479 & -3.5776 & -2.9251 & -4.1659 & -3.5084 \\
\hline 48 & -2.6142 & -1.9478 & -3.5743 & -2.9237 & -4.1613 & -3.5063 \\
\hline 49 & -2.6132 & -1.9476 & -3.5712 & -2.9224 & -4.1569 & -3.5043 \\
\hline 50 & -2.6122 & -1.9475 & -3.5682 & -2.9211 & -4.1526 & -3.5023 \\
\hline 55 & -2.6079 & -1.9468 & -3.5549 & -2.9155 & -4.1339 & -3.4936 \\
\hline 60 & -2.6043 & -1.9463 & -3.5439 & -2.9108 & -4.1185 & -3.4865 \\
\hline 65 & -2.6012 & -1.9458 & -3.5347 & -2.9069 & -4.1056 & -3.4804 \\
\hline 70 & -2.5986 & -1.9455 & -3.5269 & -2.9035 & -4.0946 & -3.4753 \\
\hline 75 & -2.5963 & -1.9451 & -3.5202 & -2.9006 & -4.0851 & -3.4708 \\
\hline 80 & -2.5943 & -1.9449 & -3.5143 & -2.8981 & -4.0769 & -3.4669 \\
\hline 85 & -2.5926 & -1.9446 & -3.5092 & -2.8959 & -4.0697 & -3.4635 \\
\hline 90 & -2.5911 & -1.9444 & -3.5046 & -2.8939 & -4.0633 & -3.4605 \\
\hline 95 & -2.5897 & -1.9442 & -3.5006 & -2.8921 & -4.0575 & -3.4578 \\
\hline 100 & -2.5884 & -1.9440 & -3.4970 & -2.8906 & -4.0524 & -3.4554 \\
\hline 150 & -2.5806 & -1.9429 & -3.4742 & -2.8807 & -4.0203 & -3.4400 \\
\hline 200 & -2.5767 & -1.9424 & -3.4631 & -2.8758 & -4.0045 & -3.4324 \\
\hline 250 & -2.5743 & -1.9421 & -3.4564 & -2.8729 & -3.9951 & -3.4279 \\
\hline 300 & -2.5728 & -1.9418 & -3.4520 & -2.8709 & -3.9888 & -3.4249 \\
\hline 400 & -2.5708 & -1.9416 & -3.4465 & -2.8685 & -3.9810 & -3.4211 \\
\hline 500 & -2.5696 & -1.9414 & -3.4433 & -2.8671 & -3.9764 & -3.4188 \\
\hline 1000 & -2.5673 & -1.9411 & -3.4368 & -2.8642 & -3.9671 & -3.4143 \\
\hline
\end{tabular}


Table 5. Calculated power of usual DF test with trend and without trend and proposed optimized test.

\begin{tabular}{ccccc}
\hline & $\beta$ & Usual DF & DF with trend & Optimized DF \\
\hline 0.0 & 0 & 0.05 & 0.05 & 0.05 \\
& 0.1 & 0.13 & 0.15 & 0.16 \\
& 0.5 & 0.20 & 0.26 & 0.28 \\
& 1.0 & 0.27 & 0.37 & 0.41 \\
& 5.0 & 0.36 & 0.49 & 0.55 \\
-0.5 & 0 & 0.45 & 0.59 & 0.67 \\
& 0.1 & 0.54 & 0.70 & 0.79 \\
& 0.5 & 0.64 & 0.78 & 0.87 \\
& 1.0 & 0.79 & 0.84 & 0.92 \\
-1.0 & 5.0 & 0.82 & 0.88 & 0.96 \\
& 0 & 0.88 & 0.92 & 0.98 \\
& 0.1 & 0.90 & 0.95 & 0.99 \\
& 0.5 & 0.95 & 0.97 & 1 \\
& 1.0 & 0.97 & 0.99 & 1 \\
& 5.0 & 0.99 & 1 & 1 \\
& 0 & 0.99 & 1 & 1 \\
& 0.1 & 1 & 1 & 1 \\
& 0.5 & 1 & 1 & 1 \\
& 1.0 & 1 & 1 & 1 \\
& 5.0 & 1 & 1 & 1 \\
& & & &
\end{tabular}

\section{Copyrights}

Copyright for this article is retained by the author(s), with first publication rights granted to the journal.

This is an open-access article distributed under the terms and conditions of the Creative Commons Attribution license (http://creativecommons.org/licenses/by/4.0/). 